\title{
DA DETERMINAÇÃO HISTÓRICA DA LÍNGUA(GEM): CONTRIBUIÇÕES DA ANÁLISE DO DISCURSO AO ENSINO DA LINGUÍSTICA
}

\section{ON THE HISTORICAL DETERMINATION OF LANGUAGE: CONTRIBUTIONS FROM THE DISCOURSE ANALYSIS TO LINGUISTICS TEACHING}

\author{
Amanda Braga ${ }^{1}$ \\ Universidade Federal da Paraíba (UFPB) \\ Israel de $\mathrm{Sá}^{2}$ \\ Universidade Federal de Uberlândia (UFU)
}

\section{RESUMO}

Partindo do pressuposto de que a relação estabelecida pela Análise do Discurso entre língua(gem) e história é o que marca sua descontinuidade em relação às demais disciplinas alocadas no interior da ciência Linguística, este artigo tem por objetivo problematizar as contribuições da Análise do Discurso ao ensino dessa ciência. Para tanto, apresenta-se uma discussão que acompanha o próprio desenvolvimento da relação entre língua(gem) e história no interior da disciplina: i) construção do objeto discurso; ii) as condições de produção do discurso e sua relação com o materialismo histórico; iii) o diálogo estabelecido com a Nova História e os trabalhos de Michel Foucault. Ao fim, demonstraremos, ainda, de que modo o arcabouço teórico-conceitual da Análise do Discurso que decorre das concepções de história adotadas pela disciplina é pensado e operacionalizado atualmente. Com este fim, mobilizaremos o conceito de memória discursiva e a noção de intericonicidade mediante a análise de duas fotografias de Lula, uma de 1979 e outra de 2018. O intuito é, enfim, demonstrar que aquilo que diferencia a Análise do Discurso das demais disciplinas linguísticas é também aquilo que ela oferece e acrescenta ao estudo da língua(gem).

PALAVRAS-CHAVE: Discurso; História; Memória.

\begin{abstract}
Based on the assumption that the relation established by the Discourse Analysis between language and history is what marks its discontinuity in relation to the other subjects from the field of Linguistic Science, this paper aims to problematize the contributions of the Discourse Analysis to the teaching of this science. For this, a discussion is presented that follows the development of the very relationship between language and history within the subject: i) construction of the discourse object; ii) the production conditions of the discourse and their relation with historical materialism; iii) the dialogue established with the New History and the works of Michel Foucault. Finally, we will demonstrate how the theoretical-conceptual framework of the Discourse Analysis that follows from the conceptions of history adopted by the subject is currently thought and operationalized. To this end, we will utilize the concept of discursive memory and the notion of interconnectivity, by analyzing two photographs of Lula, one from 1979 and one from 2018. The aim is then to demonstrate that what differentiates the Discourse Analysis from other linguistic subjects is also what it offers and adds to the study of language.
\end{abstract}

KEYWORDS: Discourse; History; Memory.

\footnotetext{
${ }^{1}$ Doutora em Letras pela Universidade Federal da Paraíba (UFPB) com período co-tutelar na Universidade Federal de São Carlos (UFSCar). E-mail: braga.ufpb@hotmail.com.

${ }^{2}$ Doutor em Linguística pela Universidade Federal de São Carlos (UFSCar). E-mail: israeldesa@ gmail.com.
} 


\section{INTRODUÇÃO}

Entre as disciplinas que, nos diferentes cursos de graduação em Letras espalhados pelo Brasil, compõem o rol da área de Linguística, está uma que se tornou bastante popular, especialmente nos anos 2000: a Análise do Discurso (por vezes, neste texto, referida apenas como AD). A despeito dessa popularidade, que já dura cerca de uma década e meia, sua entrada no currículo regular desses cursos (entre as disciplinas consideradas obrigatórias) jamais se deu de modo tranquilo e ainda, em muitas instituições, é objeto de acalorados debates. Por que isso ocorre?

Sabe-se, ao menos desde o aprofundamento do estruturalismo linguístico, em meados do século XX, que o objeto próprio da ciência linguística é a língua. Durante algumas décadas, os estudos nesse campo consideravam apenas a imanência da língua, concebida já por Saussure no Curso de Linguistica geral (2002) como sistema, ou seja, como uma estrutura completa em si, o que limitava a unidade maior de análise ao enunciado (à frase). Nota-se, portanto, que nem mesmo o texto tinha vez nesses estudos, uma vez que o mesmo extrapola os aspectos internos do sistema linguístico e vislumbra uma relação fundamental com a exterioridade da língua.

Somente na segunda metade daquele século, especialmente a partir dos anos 1960, é que a Linguística abriu espaço para o extralinguístico, na medida em se propôs a dar vez ao estudo da fala (parole), o que permitiu retomar aquilo que Saussure havia colocado em suspenso: o falante, a sociedade, a cultura, a história. Criava-se, portanto, condições para a emergência de campos de saber que sustentassem uma abordagem que ultrapassasse o estudo da frase (sem que, evidentemente, os trabalhos que se debruçavam sobre ela perdessem força), abrindo espaço para a entrada fundamental do estudo do texto e de todas as problematizações que dele emergem. Surgem, por exemplo, a Linguística Textual, a Sociolinguística, a Pragmática, a Análise da Conversação... a Análise do Discurso.

Particularmente no que se refere à Teoria (ou teorias) do Discurso, verifica-se uma especificidade substancial que a coloca num ponto de descontinuidade em relação aos demais campos e disciplinas no interior da Linguística, qual seja: a sua perspectiva interdisciplinar, caracterizada especialmente pela relação que estabelece entre Linguística e História.

Ora, mas o rótulo não apaga a diversidade? Vê-se que a multiplicidade de trabalhos neste campo recorre a autores e campos conceituais específicos e, por vezes, divergentes. Vê-se, ainda, adjetivações ou especificações nominais que buscam delimitar o que se mostra amplo: análise do discurso francesa, materialista, dialógica, pêcheutiana, foucaultiana, de Maingueneau etc. Há, no entanto, um traço comum que as atravessa, e esse traço é justamente a relação entre língua/linguagem e história.

Neste texto, cujo espaço não nos permite avançar na reflexão acerca das diferentes abordagens, centramos nossa discussão em torno da perspectiva derivada dos trabalhos de Michel Pêcheux e seu grupo que, no final dos anos 1960, propuseram teoria e método de análise dos processos discursivos, possibilitando, com isso, a fundação do campo que hoje se denomina Análise do Discurso francesa, ou Escola francesa de Análise do Discurso. Pêcheux e Fuchs (2014, p. 160), em texto crítico a respeito da proposta da Análise Automática do Discurso (2014), considerado texto fundador da disciplina (frequentemente referido como AAD-69), apontam que o quadro epistemológico desse campo reside na articulação de três regiões do conhecimento científico, atravessadas, ainda, por uma teoria da subjetividade de natureza psicanalítica, quais sejam:

1. o materialismo histórico, como teoria das formações sociais e de suas transformações, compreendida aí a teoria das ideologias;

2. a linguística, como teoria dos mecanismos sintáticos e dos processos de enunciação ao mesmo tempo; 
3. a teoria do discurso, como teoria da determinação histórica dos processos semânticos.

É perceptível, portanto, a articulação fundamental para a proposta de uma teoria do discurso entre o linguístico e o histórico, e é especialmente por isso que se verifica, ainda hoje, uma forte resistência à inclusão dessa disciplina nos currículos regulares dos cursos de Letras das universidades brasileiras.

Em nosso texto, propomos uma discussão dessa articulação que tem implicações na constituição do próprio objeto da $\mathrm{AD}$, uma vez que perpassa todas as propostas de reformulação deste campo teórico. Desse modo, iniciaremos com um breve apontamento acerca da noção de discurso para, em seguida, problematizar a articulação entre língua/linguagem e história em dois momentos: na inscrição da AD no materialismo histórico marxista e, posteriormente, no diálogo que se estabelece com a Nova História e a arqueologia de Michel Foucault. Por fim, apresentaremos um exemplo de análise, a fim de demonstrar de que modo a história pode ser mobilizada, hoje, nos estudos do discurso e, ainda, em que esse campo teórico se distingue e o que ele acrescenta aos estudos linguísticos.

\section{0 objeto da Análise do Discurso}

A Análise do Discurso nasce, como aponta Robin (1977), no interior da "ciência da história", ou seja, no seio do materialismo histórico.

Na França, a Análise de Discurso é, de imediato, concebida como um dispositivo que coloca em relação, sob uma forma mais complexa do que o suporia uma simples covariação, o campo da língua (suscetível de ser estudada pela linguística em sua forma plena) e o campo da sociedade apreendida pela história (nos termos das relações de força e de dominação ideológica) (GADET, 2014, p. 8).

É possível observar, já de início, um deslocamento na configuração de seu objeto em relação à Linguística tradicional. Se o objeto da Linguística tradicional é a língua; na Análise do Discurso, o objeto é o discurso. E, embora a língua seja parte fundamental do processo discursivo, ela não é seu centro, mas apenas um de seus eixos; é ao lado da história que a língua possibilita a configuração do discurso, o que desnuda o muito referido ponto de descontinuidade entre as duas tradições. A despeito disso, no entanto, ressalta-se que o discurso, como o concebemos, encontra na língua (e na linguagem, de modo mais amplo) seu lugar privilegiado de manifestação: a língua "é a materialidade discursiva, ou seja, o aspecto material de um discurso" (POSSENTI, 2011, p. 362).

Por isso é preciso entender, ao menos brevemente, no que consiste esse objeto singular sobre o qual nos debruçamos. Pêcheux (2014) o concebe na crítica ao famoso esquema da comunicação de Roman Jakobson, cujo aspecto central é a mensagem, tratada como transmissão de informação. Essa crítica, como aponta o próprio Pêcheux (2014, p. 81), "nos faz preferir aqui o termo discurso, que implica que não se trata necessariamente de transmissão de informação entre $A$ [locutor] e $B$ [interlocutor], mas, de modo mais geral, de um 'efeito de sentidos' entre os pontos $A$ e $B "$.

Dessa definição de discurso, nota-se um ponto elementar de sua concepção: a noção de efeito de sentidos. Possenti (2009) aponta três aspectos bastante importantes nessa definição de Pêcheux: i) não há exclusão de que o efeito de sentidos entre interlocutores seja, eventualmente, informação; ii) os sujeitos A e B, situados em lugares, ocupam posições; iii) o mais importante, trata-se sempre de efeito, e mais exatamente de efeito da atividade da enunciação: "isso porque, do ponto de vista da teoria do discurso, o sentido não está associado simplesmente nem às palavras, nem aos enunciados, mas depende, de alguma forma, exatamente da enunciação dos enunciados, o que, por sua vez, depende de condições específicas" (2009, p. 133). Possenti (2009, 
p. 134) então aponta: "o sentido é um efeito de sentido porque resulta de uma enunciação", ele é um efeito do aparecimento do significante em condições dadas; "é um efeito da enunciação do significante em situações históricas mais ou menos precisas". Em síntese, conceber os sentidos como efeito de sentidos é tomá-los como não fixos, uma vez que são produzidos em relação aos lugares ocupados pelos sujeitos na interlocução, em condições sócio históricas específicas.

O sentido de uma palavra, de uma expressão, de uma proposição etc., não existe 'em si mesmo' [...] mas, ao contrário, é determinado pelas posições ideológicas colocadas em jogo no processo sócio histórico no qual as palavras, expressões e proposições são produzidas (PÊCHEUX, 1988, p. 160).

Sendo assim, compreende-se um afastamento em relação às mais diversas linguísticas da fala que veem os lugares de enunciação como contextos situacionais. Para a Análise do Discurso, ainda que as situações imediatas de enunciação devam ser consideradas, são fundamentalmente as condições históricas de produção, e tudo que implicam (a história, a memória, a ideologia), que intervém nos processos discursivos e na produção dos efeitos de sentidos. Na sequência, nos dedicaremos a discutir essa relação que a $\mathrm{AD}$ estabelece com o elemento história: primeiramente, por sua inscrição na perspectiva marxista e, posteriormente, a partir de seu diálogo com a Nova História e a arqueologia foucaultiana.

\section{As condições de produção (o materialismo histórico)}

O primeiro elemento de vinculação entre a Análise do Discurso e a História e, mais precisamente, entre discurso e história, está na inscrição deste campo teórico no interior da reflexão marxista. Essa aproximação, como destaca Sargentini (2010, p. 96), permite observar que "os conceitos de discurso e condições de produção se entrelaçam com o conceito de ideologia e materialismo histórico". É, então, a entrada e consequente problematização do conceito de condições de produção no interior da $\mathrm{AD}$ que estabelece o vínculo inicial entre a historicidade e o linguístico no interior dos processos discursivos. Sobre este conceito, proposto em um primeiro momento da disciplina, têm-se que ele está articulado claramente à reflexão marxista, como apontam Pêcheux e Fuchs (2014, p. 162): "a região do materialismo histórico que nos diz respeito é a da superestrutura ideológica em sua ligação com o modo de produção que domina a formação social considerada".

A inscrição da história na teoria do discurso, via conceito de condições de produção, situa esse domínio, como aponta Sargentini (2010, p. 96), "no exterior linguístico, que, por sua vez, passa a estabelecer relação com o linguístico para o estudo discursivo". Pêcheux, como aponta Possenti (2011, p. 366), propõe a noção de condições de produção em oposição à de circunstância, com a finalidade de "retirar o funcionamento do discurso da cena pragmática para inseri-lo nas instâncias enunciativas institucionais, marcadas por características amplamente históricas".

O que é levado em conta, no que se refere aos participantes de um evento discursivo, não é o eventual conhecimento que tenham das regras que comandam um certo intercâmbio linguístico (digamos, que organizam um debate parlamentar), mas exatamente o que lhes escapa (ou pode lhes escapar): o fato de que cada um enuncia a partir de posições que são historicamente constituídas (fala-se como deputado de um partido, de uma frente, de situação ou de oposição, e diz-se o que se deve e se pode dizer nessa condição). O que confere ou garante o sentido ao que um enunciador diz não é o contexto imediato em que está situado e ao qual se ligam certos elementos da língua (embreadores) ou certas características do enunciado (implícitos), mas as posições ideológicas a que está submetido e as relações entre o que diz e o que já foi dito da mesma posição, considerando, eventualmente, ou em geral, que ele se opõe a uma que lhe seja contrária (POSSENTI, 2011, p. 367-368). 
Pêcheux e Fuchs (2014, p. 164) mostram ainda que o conceito de "produção" inscreve diferentes acepções em distintos campos, mas, neste caso, a significação que recebe na expressão é a de "produção de um efeito", o que permite corroborar a própria definição de discurso como efeito de sentidos entre interlocutores, que ocupam posições de sujeito historicamente constituídas e que enunciam a partir de condições sócio históricas determinadas.

Com as pesquisas de Jean-Jacques Courtine, no entanto, especialmente a partir da década de 1980, como mostra Sargentini (2010), verifica-se uma reordenação da concepção de história no campo da AD, implicada especialmente por meio de uma crítica a essa noção de condições de produção, julgada insuficiente. Por meio de novos diálogos teóricos, especialmente com os historiadores da Nova História e com a proposta arqueológica de Michel Foucault, busca-se compreender a historicidade constitutiva dos processos discursivos. É justamente disso que trataremos na sequência.

\section{A historicidade do discurso: o diálogo com a Nova História e com a arqueologia de Michel Foucault}

O deslocamento da perspectiva marxista para o diálogo com a Nova História e, em boa medida, com os trabalhos arqueológicos de Michel Foucault permitiu à Análise do Discurso, a partir da década de 1980, explicitar a historicidade dos discursos, ou seja, mostrar o caráter constitutivo da história nos processos discursivos, materializados na língua. Desde então, a história não é mais considerada um elemento da exterioridade que atravessa a língua na produção do efeito de sentidos, como propunha o conceito de condições de produção; ao contrário, a história é apreendida como própria dos processos discursivos, de modo que o material ao qual o analista tem acesso é já carregado de historicidade.

Esta reviravolta na articulação entre a teoria do discurso e a da história e, particularmente, entre o próprio objeto discurso e o elemento história que o constitui, levou também a uma revisão das práticas de constituição dos corpora discursivos. Como sabemos, a Análise do Discurso constitui todo e qualquer corpus de análise a partir de textos efetivamente produzidos - não há, neste campo, qualquer possibilidade de fabricar enunciados em "laboratório" a fim de sustentar a teoria ou a análise que se quer proceder -, mas durante muito tempo seu material foram os documentos produzidos somente no âmbito de instituições jurídicas, partidárias, estatais etc. $\mathrm{Na}$ década de 80, entretanto, há um deslocamento da leitura e abordagem dos Grandes Textos (da Ciência, da Política, do Direito, do Estado) buscando, como mostra Pêcheux (2008, p. 48), "se pôr na escuta das circulações cotidianas, tomadas no ordinário do sentido".

Sem incorrer no abandono desses textos "legitimados", há a partir de então uma abertura para a consideração daquilo que foi sempre marginalizado, daquilo que vem de baixo, colocando também em cena os sujeitos frequentemente excluídos pela história tradicional: "Este choque em retorno, obriga os olhares a se voltarem para o que se passa realmente 'em baixo', nos espaços infra estatais que constituem o ordinário das massas, especialmente em períodos de crise" (PÊCHEUX, 2008, p. 48). Do oficial, abre-se a possibilidade do enfrentamento das práticas discursivas de resistência. Nota-se, aí, o diálogo fundamental que a proposta pêcheutiana estabelece com a Nova História e com a proposta arqueológica de Michel Foucault.

Sobre Foucault, é possível afirmar que "ao dialogar com os historiadores (ao mesmo tempo rejeitado por uns e admirados por outros), combate uma história feita de causalidades e continuidades, questiona dogmas, duvida da verdade dos fatos" (SARGENTINI, 2010, p. 99). Tal postura, pulverizada por toda obra foucaultiana, é bem representada pela noção de a priori bistórico em sua relação com os enunciados e com os discursos, figurando aí como a própria "condição de realidade dos enunciados", como "as condições de emergência dos enunciados, a lei de sua coexistência com outros, a forma específica de seu modo de ser, os princípios segundo os 
quais subsistem, se transformam e desaparecem" (FOUCAULT, 2010, p. 144). Trata-se de uma proposta que considera a materialidade dos enunciados no interior dos quadros formais em que emerge, alheia às verdades invariáveis, trans-históricas e, ao mesmo tempo, às generalizações operadas por uma história tradicional. Ao contrário disso, o a priori histórico "tem de dar conta do fato de que o discurso não tem apenas um sentido ou uma verdade, mas uma história" (FOUCAULT, 2010, p. 144).

Isso significa que não se "pode" dizer qualquer coisa em qualquer tempo, pois estamos rendidos a um a priori histórico que determina regimes de verdade e condições para o dizer. Marca-se, com isso, a inscrição da descontinuidade na dispersão do tempo histórico, uma vez que a história, nessa perspectiva, compreende um emaranhado de momentos em que certas rupturas provocadas por uma mudança nas regras de formação dos enunciados discursivos provocam quebra com a linearidade até então aparente.

[...] como é possível que se tenha em certos momentos e em certas ordens de saber, estas mudanças bruscas, estas precipitações de evolução, estas transformações que não correspondem à imagem tranqüila e continuista que normalmente se faz? Mas o importante em tais mudanças não é se serão rápidas ou de grande amplitude, ou melhor, esta rapidez e esta amplitude são apenas o sinal de outras coisas: uma modificação nas regras de formação dos enunciados que são aceitos como cientificamente verdadeiros. Não é, portanto, uma mudança de conteúdo (refutação de erros antigos, nascimento de novas verdades), nem tampouco uma alteração da forma teórica (renovação do paradigma, modificação dos conjuntos sistemáticos). O que está em questão é o que rege e a forma como estes se regem entre si para constituir um conjunto de proposições aceitáveis cientificamente e, conseqüentemente, susceptíveis de serem verificadas ou infirmadas por procedimentos científicos (FOUCAULT, 1979a, p. 4, grifos do autor).

Percebe-se, aqui, uma reordenação da relação entre discurso e história, pois as rupturas que se estabelecem na linearidade histórica se dão, em grande medida, devido às inversões estabelecidas na ordem do discurso, na variação estabelecida nos regimes de verdade. Foucault (1979b), ao fazer uma releitura dos trabalhos de Nietzsche, propõe uma história genealógica, uma história que se aproxima da história-problema proposta pelos historiadores dos Annales que ainda na primeira metade do século XX problematizam os documentos.

Ao mergulhar nos documentos, ao escavar esses arquivos, esse método de análise da História encontra os discursos. É por meio da análise, mais, da problematização desses discursos encontrados sob a forma de arquivos, que se pode apanhar os movimentos da História. A base dessa movimentação está nos enunciados, em suas relações com a história; assim, analisando o modo de formação dos enunciados, pode-se estabelecer, em determinado momento histórico, os acontecimentos discursivos e as rupturas que possibilitam a emergência de um novo regime de verdade (FOUCAULT, 1979a).

É nesse sentido que Pêcheux (2008), na década de 80, propõe que é no próprio discurso que se dá o encontro entre o linguístico (a linguagem, o linguageiro) e a história (a memória), ao afirmar que o discurso é, ao mesmo tempo, estrutura e acontecimento. O discurso se realiza em uma determinada estrutura linguística, o nível da formulação, por meio de um determinado enunciado, produzindo efeitos de memória. Assim, é tarefa da $\mathrm{AD}$ buscar na formulação os enunciados que estão a ele associados, formando um domínio de memória. Pêcheux, assim como Courtine o faz em seus trabalhos do início da década de 1980, ao estabelecer diálogo com a Nova História e os estudos de Michel Foucault, inscreve a história no interior do discurso e não mais na exterioridade linguística. Pois é nesse mesmo sentido que Foucault (2010) afirma que os discursos apresentam um a priori histórico - conjuntos das regras que definem as práticas discursivas.

$\mathrm{Na}$ sequência, buscamos mostrar como esse deslocamento na compreensão da relação entre discurso e história possibilita a proposição de um arcabouço teórico-conceitual que permite 
ao analista pensar as práticas discursivas contemporâneas. Nesse sentido, abordaremos os conceitos de memória discursiva e intericonicidade, apresentando, em seguida, um exemplo de análise, a fim de demonstrar o modo como essa Análise do Discurso articulada entre Michel Pêcheux, Michel Foucault e Jean-Jacques Courtine propõe o trabalho sobre a materialidade discursiva.

\section{Um arcabouço teórico-conceitual: memória discursiva e intericonicidade}

Realizada a discussão sobre as concepções de história que perpassam as fases da Análise do Discurso e seu papel basilar no interior da disciplina, e partindo, desde já, da filiação anteriormente apontada entre os trabalhos da Análise do Discurso e os trabalhos de Michel Foucault, passaremos agora à discussão de dois conceitos que são propostos por Jean-Jacques Courtine no interior da Análise do Discurso, à esteira de sua leitura da arqueologia foucaultiana, a partir daquela década de 80 .

A obra publicada por Michel Foucault em 1969, A arqueologia do saber, é fundante, em muitos aspectos, no que se refere às ferramentas teóricas e metodológicas mobilizadas pela Análise do Discurso francesa. Um desses aspectos, para além da noção de a priori histórico, anteriormente abordada, diz respeito ao conceito de enunciado, o qual, por sua vez, é o ponto de partida para a formulação de conceitos como memória discursiva e intericonicidade, propostos por Courtine (2013).

Em $A$ arqueologia do saber, Foucault (2010) defende, como uma das condições de emergência dos enunciados, o funcionamento de um campo memória: um espaço no interior do qual o enunciado se inscreve concomitantemente a outros enunciados. Estes últimos seriam "formulações a que o enunciado se refere (implicitamente ou não), seja para repeti-las, seja para modificá-las ou adaptá-las, seja para se opor a elas, seja para falar de cada uma delas" (FOUCAULT, 2010, p. 111). Nesse sentido, ainda segundo Foucault (2010, p. 111), "não há enunciado que, de uma forma ou de outra, não reatualize outros enunciados", produzindo, dessa forma, o que Courtine (2009) entenderá como sendo um efeito de memória.

Partindo dessa relação de coexistência entre enunciados, dos efeitos de memória que daí decorrem, bem como de uma certa releitura marxista, Courtine distinguirá que "a noção de memória discursiva diz respeito à memória histórica do enunciado no interior das práticas discursivas regradas por aparelhos ideológicos" (2009, p. 105-106). Segundo o autor, é a memória discursiva que faz ecoar, numa determinada conjuntura ideológica, a posição que convém tomar, o que convém dizer ou escrever, levando-se em conta as coisas das quais nos lembramos e o modo como nos lembramos. É nesse jogo entre uma memória e sua irrupção na atualidade que se dá o funcionamento daquilo que Courtine proporá, enredado por Foucault (2010), como sendo a memória discursiva.

Por conseguinte, levando-se em conta a natureza do enunciado exposto na Arqueologia foucaultiana, isto é, sua "natureza semiológica", como observa Gregolin (2008, p. 29), a memória discursiva, tal qual formulada por Courtine (2009), poder-se-ia apresentar tanto no interior de práticas verbais quanto no interior de práticas não verbais, "permitindo a circulação e tornando possível a articulação tanto entre um já-dito e um dizer quanto entre um enunciado e sua formulação" (MILANEZ, 2006, p. 78). É, pois, dessa propriedade que decorre a noção de intericonicidade. Para circundá-la, Courtine (2013) parte da ideia de que a imagem, além de um modelo de língua, é um modelo de discurso, o que levar-nos-ia a considerar que a imagem mantém com a memória a mesma relação que um discurso verbalmente materializado mantém. Se os discursos são perpassados por memórias que os fazem significar, o mesmo acontece com as imagens: "toda imagem se inscreve em uma cultura visual, e essa cultura visual supõe existência junto ao indivíduo de uma memória visual, de uma memória das imagens onde toda imagem tem um eco. Existe um 'sempre já' da imagem” (COURTINE, 2013, p. 43). 
O que Courtine (2013) defende, com isso, é que seria possível a proposição de uma arqueologia das imagens, construída no encontro entre a história das imagens vistas e a história das imagens sugeridas. Assim, a noção de intericonicidade coloca em jogo a relação entre imagens que são internas e igualmente externas ao sujeito: um permanente diálogo entre as imagens que inventariamos individualmente e as imagens que nos são oferecidas pela cultura visual.

A intericonicidade supõe, portanto, relacionar conexões de imagens: imagens exteriores ao sujeito, como quando uma imagem pode ser inscrita numa série de imagens, uma arqueologia, à maneira do enunciado numa rede de formulações junto à Foucault; mas também imagens externas, que supõem a consideração de todo o catálogo memorial da imagem junto ao indivíduo, e talvez também os sonhos, as imagens vistas, esquecidas, ressurgidas ou até fantasiadas, que assombram o imaginário (COURTINE, 2013, p. 44).

É através da circulação dessas intericonicidades que a grande mídia, por exemplo, brinca com a memória, construindo sentidos mediante um jogo que parte da tradição e faz irromper novos discursos. Vicissitudes da mídia, sentidos da história, imagens que se cruzam: entre o dado e o novo, a intericonicidade aparece como um clarão, lançando luz sobre a produção de sentidos no interior de uma cultura visual. Seus frutos estão produzidos na instantaneidade de um acontecimento discursivo, conforme veremos a seguir.

\section{Um exemplo de análise: Lula e a multidão que o cerca}

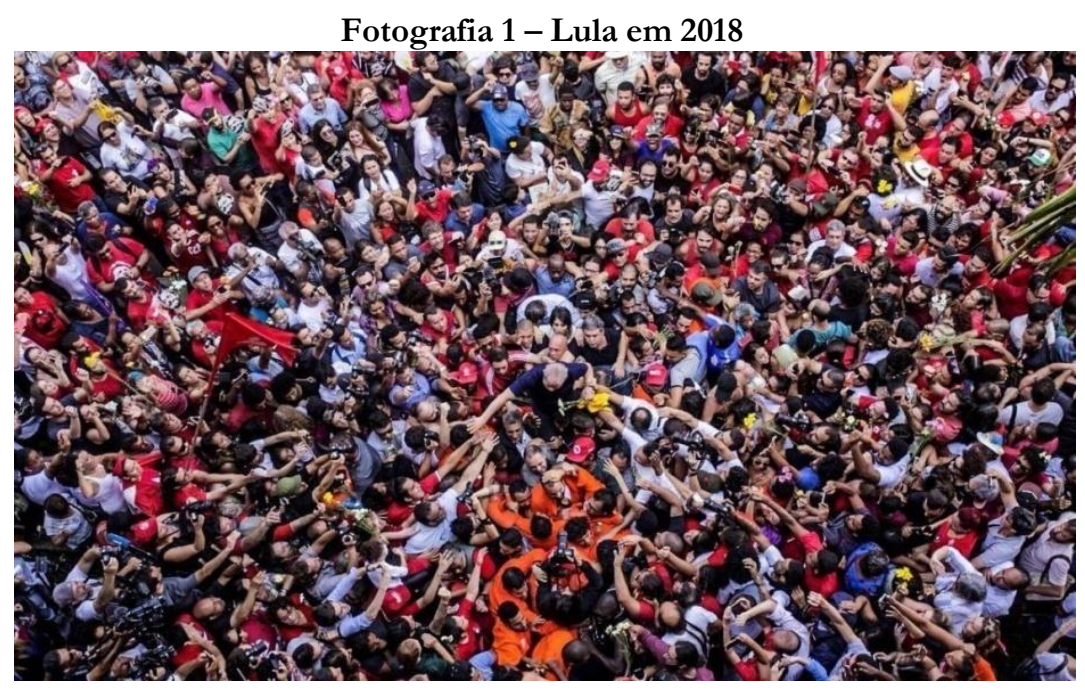

Fotografia: Francisco Proner

Em abril de 2018, após ter sido condenado em segunda instância e ter sua prisão decretada, Lula discursava em frente ao Sindicato dos Metalúrgicos do ABC, em São Bernardo do Campo. O enunciado acima, uma fotografia, flagra o exato momento em que o ex-presidente desce do carro de som e é carregado por uma multidão de apoiadores até a sede do Sindicato, de onde sairia momentos depois para se entregar à Polícia Federal. De todo material produzido e veiculado durante a mobilização, a fotografia acima foi, sem dúvida, aquela que mais circulou, nacional e internacionalmente ${ }^{3}$. Considerada, posteriormente, como uma das imagens do ano de $2018^{4}$, a fotografia guarda sua força não apenas pela sua capacidade de narrar o ápice de uma

\footnotetext{
${ }^{3}$ Essa fotografia aparece em jornais como The New York Times, The Guardin e El País, quando da notícia acerca da prisão de Lula.

4 Disponível em: <https://pt.org.br/foto-do-abraco-a-lula-de-francisco-proner-e-escolhida-imagem-do-ano/>. Acesso em: 19 fev. 2019.
} 
histórica mobilização política e popular, mas também pela sua capacidade de fazer emergir a memória outra fotografia, produzida quase 40 anos antes.

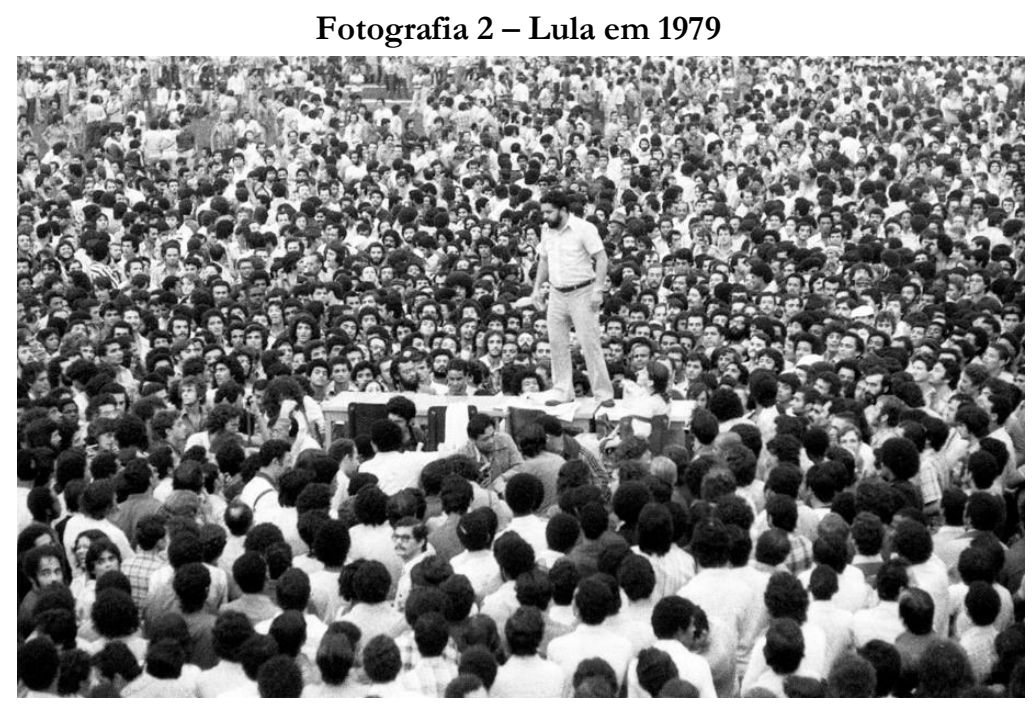

Fotografia de domínio público

Em março de 1979, a mesma sede do Sindicato dos Metalúrgicos do ABC havia sido palco da primeira greve geral de uma categoria no país, desde a paralisação de Contagem (MG), em 1968: 200 mil metalúrgicos desafiavam a grande indústria automobilística da região e a repressão do governo militar. Diante da massiva adesão dos trabalhadores ao movimento, as assembleias deixaram de ser na sede do Sindicato para ser no Estádio Municipal Vila Euclides, cedido pelo então prefeito da cidade. Neste segundo enunciado, também uma fotografia, tão histórica quanto a primeira, em cima de uma mesa de escritório improvisada enquanto palco, e sem qualquer sistema de som que pudesse amplificar e transmitir sua voz, Lula, cercado de trabalhadores, usava um megafone: aqueles que estavam próximos ao então sindicalista transmitiam suas palavras, em coro, aos que estavam mais afastados.

Entre os dois enunciados ou, ainda, entre o ex-presidente condenado da primeira fotografia e o metalúrgico sindicalista da segunda, ambos cercados por uma imensa mobilização popular que os reconhece enquanto líderes, há "um fio tênue, mas tenaz, que atravessa e tece a teia das palavras e das imagens" (COURTINE, 2013, p. 24). Esse fio é a própria história, a memória das imagens, o funcionamento da intericonicidade, e é justamente ele que justifica a massiva distribuição do primeiro enunciado quando da prisão de Lula, em abril de 2018.

Para fazer jus à espessura histórica que atravessa e é constitutiva dos enunciados aqui postos, poder-se-ia partir da discussão empreendida por Courtine (2015) sobre o final do século XIX e o início do século XX: é esse momento histórico que nos possibilita abordar a emergência dos discursos sobre a multidão e seu líder, justamente porque é esse momento histórico que flagra o nascimento das grandes cidades e a emergência das sociedades de massa. É no século XIX que as grandes aglomerações humanas fariam emergir a multidão enquanto acontecimento histórico e objeto de pensamento, acerca das quais seriam postas questões até então inéditas: como dominar o poder e a fúria das multidões, como convencê-las e guiá-las?

Retomando as obras de Le Bon (1896) e de Emile Zola (1968), Courtine (2015) mostrará que surge, aqui, uma caracterização da multidão assentada em um modelo arcaico de dominação: as multidões seriam femininas e seu estado psicológico perpassaria sentimentos como "a impulsividade, a irritabilidade, a inconstância, os exageros e simplificações dos sentimentos, a credulidade", ou, ainda, a irracionalidade e a imprevisibilidade (COURTINE, 2015, p. 266). Pelo mesmo motivo - o modelo de dominação -, presume-se a necessidade de um líder. Mais que 
isso: um líder carismático que não apenas seja oriundo da multidão, posto que "a voz do povo emerge do corpo do povo" (COURTINE, 2015, p. 281), mas que também fale em seu nome e a seu modo, fazendo surgir uma eloquência proletária que marca o distanciamento da fala pública dos manuais de retórica e uma aproximação da mesma com rusticidade do trabalho manual.

Tal rusticidade, que marcaria a fala pública do líder justamente porque é também ela que marca a fala da multidão da qual o mesmo se origina, selaria "um antigo, consolidado e duradouro imaginário sobre a voz do povo. A multidão vocifera, protesta, geme ou delira - de raiva ou de prazer: a massa não fala" (COURTINE, 2015, p. 271). O povo, nesse sentido, colocaria em xeque a estabilidade da clássica organização das cenas oratórias, nas quais o orador detém o poder da palavra diante de uma multidão silenciosa. A voz do povo não se situa nem no silêncio e nem tampouco na articulação da fala: sua expressão está, antes, em murmúrios e burburinhos coletivos, em explosões nervosas e inflamadas emoções.

É nesse cenário, que engloba uma multidão enfurecida e, ao mesmo tempo, um líder eleito e construído à sua imagem e semelhança, que se dá a tentativa de fechamento das massas: uma domesticação ou uma gestão das grandes populações, tal qual discutiu Foucault (2008) em relação à governamentalidade. A formação de partidos políticos é um exemplo desse processo.

Feita essa digressão, se voltamos aos enunciados apresentados inicialmente, resta evidente que os discursos que estão presentes e que compõem tais enunciados não estão presos ao momento histórico em que foram produzidos. Ao contrário disso, a construção discursiva do líder popular, que não apenas fala pelo povo como também se origina dele - presente em ambos enunciados - está posto em uma duração que remete, pelo menos, ao século XIX.

O enunciado em que está retratado o Lula sindicalista, produzido no auge da greve dos metalúrgicos, em 1979, flagra mais do que seu pronunciamento em um estádio esportivo. O enunciado flagra o próprio fechamento de uma massa que estava, até ali, dispersa sob a forma de minorias em greve. O enunciado flagra, além disso e principalmente, o nascimento de seu líder, o qual, assim como o previu Le Bon (1896), não apenas emergiu da própria multidão como também, em seu corpo, carrega os traços do trabalho manual: seus gestos corporais, sua roupa informal, sua barba, seus cabelos, ressoam a brutalidade do trabalho operário.

O enunciado que retrata o Lula ex-presidente, por sua vez, quase 40 anos além, flagra o retorno das multidões às ruas, agora não mais para escolha e reconhecimento de seu líder, mas para defesa da sua história. Por um lado, bem como na fotografia anterior, ainda que a imagem tenha sido produzida em outro ângulo, a organização dos indivíduos se dá de modo análogo: uma imensa multidão em torno de Lula, ao centro da imagem. Por outro lado, ao contrário da fotografia anterior, em que Lula estava em cima de uma mesa, aqui, o ex-presidente está, literalmente, nos braços do povo, mistura-se e confunde-se com ele, num apagamento dos limites individuais e das distâncias que os separam, porque agora, mais do que nunca, é preciso ratificar sua origem.

Não é aleatória, portanto, a ida de Lula ao Sindicato momentos antes de sua prisão, tampouco é aleatória a escolha da fotografia que viria a ser reproduzida em escala global. O que está em jogo, naquele acontecimento, é a retomada de uma memória que atualiza a história e a construção de um líder popular, realizada a partir de dois enunciados em relação de intericonicidade.

Toda essa dimensão histórica aqui resgatada é, por fim, constitutiva dos enunciados analisados, é ela quem possibilita sua constituição, sua emergência e sua produção de sentido, de modo que não poderia jamais ser negligenciada numa análise discursiva. Frisa-se, por fim, que tal análise, no entanto, não seria possível se lançássemos mão apenas do conceito de condições de produção, no qual a história é um elemento exterior que perpassa o enunciado. Uma análise dessa natureza requer, justamente, a consideração de um a priori histórico como "condição de realidade para os enunciados", como condição própria de sua emergência: como "a lei de sua coexistência 
com outros, a forma específica de seu modo de ser, os princípios segundo os quais subsistem, se transformam e desaparecem" (FOUCAULT, 2010, p. 144).

É precisamente por este motivo que este artigo, no intuito de demonstrar aquilo que a Análise do Discurso pode oferecer ao ensino da Linguística, insistiu na espessura histórica do objeto de análise.

\section{CONSIDERAÇÕES FINAIS}

Ao longo deste texto, cujo objetivo primeiro foi demonstrar aquilo que a Análise do Discurso pode oferecer ao ensino da Linguística, foi possível observar, em diferentes momentos de seu percurso, o modo como se dá a articulação entre língua/linguagem e história no interior dos estudos do discurso e, com isso, os elementos que implicam a descontinuidade desse campo teórico em relação à ciência linguística. É justamente o fato de considerar ora as condições de produção, ora o a priori histórico, afastando-se da noção de contexto própria da Pragmática ou da Linguística Textual, que oferece à $\mathrm{AD}$ a especificidade dos processos discursivos.

Atualmente, enfim, a Escola francesa de Análise do Discurso aponta para uma análise comprometida com o trabalho da história na constituição dos enunciados, os quais são pensados no interior de um a priori histórico que possibilita e os oferece condições de emergência, porque é preciso "dar conta do fato de que o discurso não tem apenas um sentido ou uma verdade, mas uma história" (FOUCAULT, 2010, 144). Foi isso que tentamos demonstrar mediante a análise das duas fotografias de Lula e é essa, enfim, a contribuição oferecida pela Análise do Discurso ao ensino da Linguística.

\section{REFERÊNCIAS}

COURTINE, J.-J. Análise do Discurso: o discurso comunista endereçado aos cristãos. São Carlos: EdUFSCar, 2009.

COURTINE, J.-J. Decifrar o corpo: pensar com Foucault. Petrópolis: Vozes, 2013.

COURTINE, J.-J. A voz do povo: a fala pública, a multidão e as emoções na aurora da era das massas. In: COURTINE, J.-J.; PIOVEZANI, C. (Org.). História da fala pública: uma arqueologia dos poderes do discurso. Petrópolis: Vozes, 2015. p. 261-289.

FOUCAULT, M. Verdade e poder. In: FOUCAULT, M. Microfísica do poder. Rio de Janeiro: Edições Graal, 1979a. p. 1-14.

FOUCAULT, M. Nietzsche, a genealogia e a história. In: FOUCAULT, M. Microfísica do poder. Rio de Janeiro: Edições Graal, 1979b. p. 15-37.

FOUCAULT, M. Segurança, território e população: curso dado no Collège de France (19771978). São Paulo: Martins Fontes, 2008.

FOUCAULT, M. A arqueologia do saber. Rio de Janeiro: Forense Universitária, 2010.

GADET, F. Prefácio. In: GADET, F.; HAK, T. (Org.). Por uma análise automática do discurso: uma introdução à obra de Michel Pêcheux. Campinas: Editora da UNICAMP, 2014. p. 7-10. 
GREGOLIN, M. R. J.-J. Courtine e as metamorfoses da Análise do Discurso: novos objetos, novos olhares. In: SARGENTINI, V.; GREGOLIN, M. R. (Org.). Análise do Discurso: heranças, métodos e objetos. São Carlos: Claraluz, 2008. p. 21-37.

LE BON, G. La psycologiedesfoules. Paris: Alcan, 1896.

MILANEZ, N. As aventuras do corpo: dos modos de subjetivação às memórias de si em revista impressa. Tese (Doutorado em Linguística e Língua Portuguesa). Faculdade de Ciências e Letras de Araraquara, Universidade Estadual Paulista, 2006.

PÊCHEUX, M. Semântica e discurso: uma crítica à afirmação do óbvio. Campinas: Editora da Unicamp, 1988.

PÊCHEUX, M. Delimitações, inversões e deslocamentos. Cadernos de estudos linguísticos, Campinas, v. 19, p. 7-24, jul./dez. 1990.

PÊCHEUX, M. O discurso: estrutura ou acontecimento. Campinas: Pontes, 2008.

PÊCHEUX, M. Análise automática do discurso (AAD-69). In: GADET, F.; HAK, T. (Org.). Por uma análise automática do discurso: uma introdução à obra de Michel Pêcheux. Campinas: Editora da UNICAMP, 2014. p. 59-158.

PÊCHEUX, M.; FUCHS, C. A propósito da análise automática do discurso: atualização e perspectivas. In: GADET, F.; HAK, T. (Org.). Por uma análise automática do discurso: uma introdução à obra de Michel Pêcheux. Campinas: Editora da UNICAMP, 2014. p. 159-249.

POSSENTI, S. Os limites do discurso: ensaios sobre discurso e sujeito. São Paulo: Parábola Editorial, 2009.

POSSENTI, S. Teoria do discurso: um caso de múltiplas rupturas. In: MUSSALIN, F.; BENTES, A. (Org.). Introdução à linguística: fundamentos epistemológicos. v. 3. São Paulo: Cortez, 2011. p. 353-391.

ROBIN, R. História e Lingüística. São Paulo: Cultrix, 1977.

SARGENTINI, V. As relações entre a Análise do Discurso e a História. In: MILANEZ, N.; GASPAR, N. R. (Orgs.). A (des)ordem do discurso. São Paulo: Contexto, 2010. p. 95-102.

SAUSSURE, F. Curso de Linguística geral. São Paulo: Cultrix, 2002.

ZOLA, E. Germinal. Paris: Garnier/ Flammarion, 1968.

Submetido em 05/08/2019

Aceito em 29/11/2019

Publicado em 06/12/2019 